\title{
Cartilage Tissue Engineering: An Update on Multi-Component Approach
}

Keywords: Cartilage injury; Osteoarthritis; Regenerative medicine; Stem cell-based therapy; Biomaterials; Growth factors

\begin{abstract}
Cartilage injury and osteoarthritis are big clinical challenges as self-healing potential of cartilaginous tissue is very limited. The need for a multi-disciplinary approach in order to establish new strategies for cartilage healing has been addressed by many scientists from the fields of orthopaedic surgery or biomedical engineering in the last two decades. With a focus on the very preclinical research in this field, this review covers the multitude of approaches, ranging from cellbased to scaffold-based strategies and also including growth factors, precondition approach, mechanical stimulation-that have been combined to assess their potential to develop effective concepts for the treatment of cartilage injury or osteoarthritis.
\end{abstract}

\section{Epidemiology of Cartilage Injury and Osteoarthritis}

Cartilage injury (also called chondral injury) is known as the lesion within cartilage layer, while osteochondral injury is the fullthickness lesion extending to the subchondral bone. Cartilage injury or osteochondral injury is common in sport injuries [1], road traffic accidents [2], and other trauma. An epidemiological study on 31,516 knee arthroscopies in USA reported that $63 \%$ of patients had chondral lesions (averaging 2.7 lesions per knee) and 20\% had fullthickness lesions, with $5 \%$ of these occurring in patients less than 40 years of age [3], $65 \%$ of them were accompanied with meniscal or ligament lesions, mostly anterior crucial ligament (ACL) tear $[3,4]$. In subgroup analysis, $75 \%$ of young patients below 40 years old had solitary chondral lesions and; the remaining $25 \%$ had multiple lesions. Another similar study conducted in Poland examining a total of 25,124 knee arthroscopies, reported that chondral lesions were found in $60 \%$ of these patients. Medial meniscus tear (37\%) and ACL injury (36\%) were the most frequent associated factors [5].

Cartilage is categorized into three types including hyaline cartilage, elastic cartilage, and fibro cartilage according to its composition. Articular cartilage is a tough but flexible hyaline cartilage that covers the ends of bones at a joint, which functions as a cushion allowing smooth joint movement. As articular cartilage injuries can occur focally, which is localized and contained, or globally, which can finally lead to joint Osteoarthritis (OA) - the most common chronic joint disease. $\mathrm{OA}$ is a chronic degenerative disease mainly happened in elderly with destruction of articular cartilage and subchondral bone sclerosis, which is distinct from acute cartilage injury. Data from 2010 to 2012 showed that one in five, or 52.5 million, USA adults had arthritis; one in nine, or 22.7 million, had arthritis-attributable activity limitations [6]. Recently, it was reported that more than fifty million of the population over 60 years old in mainland China were affected by joint pain that may be attributed to osteoarthritis [7]. A local survey in Hong Kong on men aged 50 years and above revealed that $17 \%$ and $7 \%$ had persistent knee pain and OA, respectively. The prevalence in women was higher, being $24 \%$ and $13 \%$, respectively [8].

\section{Journal of Orthopedics \& Rheumatology}

\author{
Zong $Z^{1}$, Wu $X^{1,2}$, Su $Z^{1}$, Wang $Z^{1}$, Zhao $Z^{1}$, \\ Huang $\mathbf{J}^{\mathbf{3}}$, Zhong $\mathbf{C}^{\mathbf{4}}$, Wei $\mathbf{B}^{1}$, Li G $\mathbf{G}^{\mathbf{5}}$ and Lin $\mathbf{S}^{\mathbf{1}, 2, \mathbf{6}^{*}}$ \\ ${ }^{\prime}$ Orthopaedic Center, Affiliated Hospital of Guangdong Medical \\ University, Guangdong Medical University, China \\ ${ }^{2}$ Marine Biomedical Research Institute, Guangdong Medical \\ University, China \\ ${ }^{3}$ Department of Stomatology, Guangdong Medical University, China \\ ${ }^{4}$ Institute of Laboratory Medicine, Guangdong Medical University, \\ China \\ ${ }^{5}$ Department of Orthopaedics and Traumatology, The Chinese \\ University of Hong Kong, China \\ ${ }^{6}$ Department of Orthopaedic Surgery, Stanford University, USA \\ *Address for Correspondence \\ Lin S, Department of Orthopaedic Surgery, School of Medicine, Stanford \\ University, 300 Pasteur Drive, Edwards R163, Stanford, CA 94305, USA; \\ E-mail: sienlin@stanford.edu \\ Submission: 08 November 2019 \\ Accepted: 05 December 2019 \\ Published: 12 December 2019 \\ Copyright: (c) 2019 Zong Z, et al. This is an open access article \\ distributed under the Creative Commons Attribution License, which \\ permits unrestricted use, distribution, and reproduction in any medium, \\ provided the original work is properly cited.
}

\section{Healing Process of Cartilage Injury}

Cartilage is an avascular tissue with minimal supply of nutrients and progenitor cells from circulation, and composed of limited number of chondrocytes with low mitotic potential, making cartilage a poor self-regenerating tissue in response to injury [9]. In cartilage, nutrients and wastes exchange are achieved through synovial fluid perfusion, which also allow the delivery of various factors participating in healing [9]. Scarce resident stem cells in cartilage are identified recently, which require considerable manipulation efforts to generate cartilage in vitro [10]. Chondroclasts have only been described for calcified or hypertrophic matrices, which are proposed to play a role in cartilage remodeling. Tiny defects are healed by migration of chondrocytes, while large defects are healed by formation of biomechanically incompetent fibrocartilage [11]. Hence, cartilage lesions seldom heal spontaneously and thus constitute one of the main causes of joint disease and disability $[12,13]$. Given that persistent cartilage defects gradually lead to degeneration of the articular cartilage and osteoarthritis [11], the restoration of cartilage integrity through the promotion of cartilage regeneration has been a research question over the decades.

\section{Traditional Treatments for Cartilage Injury or Osteoarthritis}

Primary treatments options including protecting from further injury, ice cooling, and analgesic may help to settle the initial pain and swelling after acute cartilage injury. Further surgical treatments are subjected to the severity of cartilage lesion. Several surgical techniques are readily available to treat cartilage injuries of the knee upon different 
scenarios [14]. Amount of all, operations like arthroscopic lavage, debridement, microfracture, Autologous Chondrocyte Implantation (ACI), and Osteochondral Autograft Transplantation (OAT) are most widely used nowadays encountering to the cartilage lesions [15]. These reparative methods are tended to stimulate the formation of new fibrocartilage tissue by facilitating access to the vascular system and bringing new progenitor cells capable of chondrogenesis (e.g., microfracture procedure and drilling). Reconstructive methods fill up the defects with autologous, homologous, or other tissue (e.g., autologous chondrocyte implantation and osteochondral autologous transplantation) $[16,17]$. Such methods may associated with good outcomes after surgery, but according to a systematic review of level I and II studies on OAT procedures and microfracture surgery showing that, patients with small lesions who returned to higher-demand activities had an higher progressive failure rate and only $52 \%$ of athletes returned to sports after received microfracture surgery, 37\% of them retained their same level of sports 10-year after operation $[18,19]$. Besides, another systematic review reported by Filardo et al. revealed that $33.7 \%$ failure rate at a mean was recorded follow-up of 8.5 years after ACI surgeries (5-12 years post-surgery) in 193 patients [20].

The therapeutic strategies for $\mathrm{OA}$ are distinct from acute cartilage injuries. Chronic pain relief could be achieved with lifestyle modification and medication such as Non-Steroidal AntiInflammatory Drugs (NSAIDs) or glucocorticoid. NSAIDs are the most widely prescribed pharmacological medications and were recommended in the guidelines in the treatment of OA but longterm administration are associated with serious side effects including bleeding and perforated gastric ulcers [21-23]. Long-term use of glucocorticoid may cause several side effects such asimmunodeficiency, osteoporosis, peptic ulcer disease or gastrointestinal bleeding [24,25]. Viscosupplementation with hyaluronic acid through intra-articular injection helps to reduce OA caused pain through its lubricating action, but recent clinical studies showed that the use of hyaluronic acid did not improve clinical outcomes compared to the placebo group significantly $[26,27]$.

However, these current treatments are not promising solution to prevent articular cartilage from further progressive destruction, thus OA patients may need joint replacement to regain reasonable joint movement at the expense of potential complications. Although the shelf life of prosthetics for joint replacement is significantly improved, this surgery remains less suitable for young OA patients $[28,29]$. Thus, there is a burning need for alternative approaches to manage cartilage lesions, which would prevent the early onset of $\mathrm{OA}$ and to reduce the need for total joint replacement.

\section{Biological Solutions for Cartilage Repair}

Autologous Chondrocyte Implantation (ACI) is a convincing and effective method for the treatment of cartilage lesions [30,31]. The usefulness of allogeneic chondrocytes as alternative source was constrained because of the reported immunogenicity [32]. Furthermore, in vitro expansion of chondrocytes can lead to rapid dedifferentiation and a fibroblastic phenotype [30], resulting in an inferior tissue-engineered cartilage.

Mesenchymal Stem Cells (MSCs) are a promising and readily available cell source showing chondrogenic differentiation potential and forming cartilage-like tissues in vitro induced by specific growth factors without compromising its low immunogenicity [33-37]. MSCs can be derived from various types of tissues, including bone marrow [38,39], adipose tissue [40], tendon [41,42], synovial membrane [43], dental pulp [44], umbilical cord blood [45], placenta [46,47], etc.

Autologous MSCs are currently the major cell source because of ethical and immunological concerns. However, a major drawback of their clinical use is the aging-related decline in MSCs proliferation and chondrogenic differentiation potential from aged patients (donors) and in vitro cell culturing as several studies had reported that MSC isolated from older donors exhibited a slower proliferation rate throughout the entire in vitro expansion compared with the younger donors. And the shorter average length of telomere, loss of telomere length after cell passage and lower levels of telomerase activity may contribute to such phenomenon. Besides, the expression of p16INK4A is also strongly associated with cell senescence [4851]. Furthermore, instable MSCs phenotypes such as formation of mineralized deposits within cartilage. Current available strategies for enhancing plasticity of MSCs included genetic modification [52$54]$, hypoxia stimulation $[55,56]$, etc. However, safety and ethical concerns are existed for genetic modification approach, which is left far behind clinical use, and hypoxia could only promote cell proliferation at this stage. Hence, it is mandatory to find out a simple and feasible manipulation for promoting plasticity of MSCs including proliferation, chondrogenesis and viability.

\section{Dedifferentiation Reprogrammed MSCs for Tissue Regeneration}

Cellular dedifferentiation is cellular regression from a more differentiated stage back to a less differentiated stage from within its own lineage that confers pluripotency, giving rise to reminiscent of stem cells $[57,58]$. Based on this definition, cellular dedifferentiation is not only initiating from a completely differentiated stage, but also initiating from partially differentiated stage. Similarly, cellular dedifferentiation could result in partially or fully pluripotent cells, depends on the different time points. This process is more commonly studied in plants and more primitive creatures. Several non-mammalian vertebrate species, such as zebra fish and urodele amphibians [59-65], possess a remarkable capacity to regenerate heart tissue or limb, respectively. Apart from natural conditions, researchers found that inducible dedifferentiation is an appropriate strategy to promote regeneration in mammalian tissues that lack of this ability. Studies have reported the occurrence of cell dedifferentiation during tissue regeneration both in vitro and in vivo [66-70].

Recent studies have demonstrated that dedifferentiation reprogramming is a reliable method to improve properties of stem cells and promote lineage differentiation commitment [71-73]. Previous data revealed that a population of MSCs with enhanced viability in vitro and improved therapeutic efficacy in a cerebral ischemia model could be attained via neuronal differentiation and dedifferentiation reprogramming [72]. Recently we reported that, compared with untreated MSCs, MSCs which manipulated with osteogenic differentiation medium exhibited a better osteogenic differentiation potential, improved cell migratory capacity and upregulated expression of genes Nanog, Oct4 and Sox2 [74]. And we 
ISSN: $2334-2846$

Table 1: Selected growth factors and their effects on MSCs.

\begin{tabular}{|c|c|}
\hline Growth factor & Effects on MSCs \\
\hline TGF- $\beta 1$ & Increases proliferation and cartilaginous ECM production, downregulates collagen type I gene expression [79] \\
\hline TGF- $\beta 3$ & Increases cartilaginous ECM production [82] \\
\hline BMP-2 & $\begin{array}{l}\text { Turns on the chondrogenic pathway in the appropriate chondrogenic precursor cell pool and Repairs cartilage-bone interface tissue defects } \\
\qquad[79,80]\end{array}$ \\
\hline GDF-5 & Increases cartilaginous ECM production [78] \\
\hline IGF-1 & Increases proliferation and cartilaginous ECM production, additive effect on chondrogenesis with TGF- $\beta 1$ and BMP-7 [84] \\
\hline BMP-4 & Accelerates the progression of cartilage differentiation to maturation [78] \\
\hline BMP-6 & upregulates chondrogenic genes and downregulates genes associated with chondrocyte hypertrophy and endochondral ossification[80] \\
\hline BMP-7 & Inhibits cell proliferation, induces chondrogenic differentiation, additive effect on chondrogenesis with TGF- $\beta 1$ and IGF-1 [85,86] \\
\hline BMP-9 & Maintains the expression of chondrocyte-specific ECM molecules in the presence of OA-related physiological levels of IL-1 [80] \\
\hline FGF-2 & Increases proliferation, increases proteoglycan production [87] \\
\hline
\end{tabular}

also proved that such improvements were inducted by decreased methylation and accrual of activating histone marks of promoters on Nanog and Oct4.Besides, after preconditioned with chondrogenic differentiation medium and complete medium, the Manipulated MSCs (M-MSCs) also showed an improved cell clonogenicity, proliferation, survivability and chondrogenic property. And the results of epigenetic analysis revealed the central role of Nanog in maintaining the multipotency of the manipulated MSCs [75]. Furthermore, we also revealed that neocartilage formation of M-MSC-laden constructs implanted in the nude mice was significantly promoted after dynamic compressive applied in the bioreactor and the constructs laden with M-MSCs were also significantly promoted the cartilage healing process of osteochondral defect of a rat model [76].

\section{Growth Factors for Chondrogenic Differentiation}

In the hyaline cartilage, growth factors regulate homeostasis and integrity, as well as development [77]. Growth factors also play an important role in the process of chondrogenic differentiation of MSCs. Table 1 summarizes some representable endogenous bioactive cytokines, including Transforming Growth Factor $\beta$ (TGF- $\beta$ ) superfamily with respect to cartilage tissue engineering are TGF- $\beta 1$, TGF- $\beta 3$, Bone Morphogenetic Protein 2(BMP-2), BMP-4, BMP-6, BMP-7, BMP-9 and Growth Differentiation factor-5 (GDF5) $[78-81]$, which are reported to stimulate MSCs proliferation and differentiation. Among of these, TGF- $\beta 1$ and TGF- $\beta 3$ are the most frequently used cytokines in experimental studies to promote chondrogenic differentiation and synthesis of corresponding Extracellular Matrix (ECM) production [79,81-83] (Table 1).

\section{Biomaterials for Cartilage Repair}

Various materials in the form of sponges, hydrogels, electrospun fibers, and microparticles have been fabricated as scaffolds to support chondrogenic differentiation [89]. Natural biomaterials, derived from either polymer (agarose, alginate, chitosan, and hyaluronan) or protein (collagen, gelatin, fibrin, and silk) are biocompatible but have poor mechanical strength and relatively high degradation rate in most cases without proper modification [90,91]. Synthetic biodegradable polymers offer some important advantages such as controllable degradation rate, high reproducibility, high mechanical strength, and easy manipulation into specific shapes. However, the cell recognition signals are usually missing in such scaffolds [92]. When stem cells are applied to cartilage defects, direct administrations of stem cells into cartilage defects often lead to limited cartilage regeneration due to significant cell loss and death as a result of the harsh mechanical loading and catabolic factors in the diseased joints [93]. The lack of a functional carrier material to provide physical retention and biochemical cues to the delivered cells in the cartilage defects results in poor retention, significant death and unsatisfactory differentiation of the cells [94]. Therefore, there exists a huge demand for effective carrier biomaterials that afford not only physical support but also biochemical signals to the delivered cells in order to promote the cartilage repair. As articular cartilage is totally covered by the articular capsule, it will be much helpful to deliver the cells through a minimal invasive way, such as intra-articular injection.

Among all of these materials, natural polymer like Hyaluronic Acid (HA) has been intensively investigated. HA can be modified to photo-crosslink into 3D hydrogels that confers chondrogenesis properties of MSCs [95]. The superior mechanical stiffness and network porosity and permeability have positive impact on the differentiation of encapsulated MSCs [96-99], distribution of newly synthesized cartilage matrix, and nutrition transportation [100, 101]. Previous data showed enhanced chondrogenic differentiation and inhibited hypertrophy could be achieved by modulating cross linking density of HA macromer $[102,103]$. Besides, after modified Quantum Dots (QDs) with $\beta$-Cyclodextrin ( $\beta$-CD) and RGD peptide, the manipulated nanocarrier gained the ability of carrying hydrophobic small molecules such as kartogenin in the hydrophobic pockets to induce chondrogenic differentiation of human mesenchymal stem cells [104]. Moreover, after conjugated sulfate groups to HA, these modified sulfated HA exhibit a higher protein affinity and significantly slower degradation by hyaluronidase with no negative effect on the viability of human Mesenchymal Stem Cells (hMSCs) compared to the wild type HA hydrogel, which results the avert of cartilage abrasion and hypertrophy in the osteoarthritis joints of a rat model of OA [105].

Compared with HA, after proper modification, gelatin hydrogel also exhibited an excellent capacity of self-healing and improved 
physical and biological properties. Recently, cyclodextrin-based host-guest interact with gelatin are of great interest because of its effectiveness and specificity of host-gust molecular recognition under physiological condition which can be facilitated to form supramolecular hydrogels. In our recent study, we revealed that thought crosslinked acrylated $\beta$-cyclodextrins (Ac- $\beta$-CDs) with the aromatic residues of gelatin by in situ formed multivalent host-guest nanoclusters under UV-initiated oligomerization, the as-prepared hydrogel shown a significantly enhanced mechanical strength thanks to its reversible nature of the host-guest interactions. Those interactions enables the hosts and guests moieties to re-form the hostguest cross-links thus preventing the early rupture of the polymer Besides, the Host-Guest Macromer (HGM) hydrogels also exhibited improved compressive properties with much faster stress relaxation rate. Such enhanced compressibility and fast stress relaxation property facilitate the HGM hydrogels to fit into irregular geometries without compromising the hydrogel integrity [106]. Moreover, the HostGuest Macromer (HGM) hydrogels were also able to sustain release of encapsulated therapeutic growth factors and deliver therapeutic cells. In animal study, we also demonstrated that such novel HGM hydrogel could significantly promoted the cartilage regeneration in a rat model [106]. In our subsequent study, we also demonstrated that the injectable stem cell-laden HGM hydrogels could remarkably boost the regeneration of both cartilage and subchondral bone in an osteochondral defect model after encapsulated human Bone Marrowderived Mesenchymal Stem Cells (hBMSCs) with small molecule (Kartogenin) and proteinaceous chondrogenic agents (TGF- $\beta 1$ ). Data also showed that the injection process only has a minor negative impact on cell viability and chondrogenic differentiation capacity of the cells encapsulated in the hydrogels which indicated that such biomaterial and cell delivery method could greatly facilitate stem cell therapies [107].

\section{Mechanical Stimulation and Chondrogenic} Differentiation

Mechanical stimulation with bioreactors on cell-seeded constructs is a well-established cue for improving the mechanical properties of tissue-engineered cartilage $[108,109]$. Direct confined or unconfined compression and hydrostatic pressure are the two most investigated loading regimes in cartilage tissue engineering studies. Direct dynamic compression applied to chondrocyte-seeded constructs generally increased ECM production and proliferation of chondrocytes, and improved compressive properties of the engineered tissue [110-117]. Mechanical forces generated intrinsically within the cell in response to its extracellular environment, and extrinsic mechanical signals imposed upon the cell by the extracellular environment, play a critical role in determining the fate of MSCs [118-120]. Mechanical signals have also been reported to induce chondrogenesis of bone marrowderived MSCs and inhibit subsequent hypertrophy as effectively as TGF- $\beta 1$ stimulation [121-125]. Compressive loading is the most frequently used protocol for promoting chondrogenesis of MSCs. A combination of TGF- $\beta 1$ and compressive loading presents a synergistic effect on chondrogenic differentiation [126]. Apart from compressive loading, fluid flow has also been shown to upregulate Sox9 gene expression in murine C3H10T1/2 MSCs plated onto glass slides [127]; tensile strain regulated chondrogenic differentiation and GAG synthesis by MSCs embedded in collagen-GAG [128].

\section{Conclusion}

With aging and rising of obesity, cartilage injury and osteoarthritis has become major healthcare problems worldwide. The biological approaches showed a great therapeutic potential in the treatment of cartilage injury or OA. However, open questions and challenges are existed and remained to be settled, as most of the studies are still at early stage and evidences such as long-term and large-scale study are still needed. Besides, the problem of stability of the growth factors, survival rate of the cells encapsulated in the biomaterial and large-scale fabrication are still challenging the process of final commercialization. Taken all these together, till now, even bioactive scaffold cannot completely meet every request in the clinical application; we still believe that biological functionalization solutions are the future direction for the treatment of cartilage injury and osteoarthritis.

\section{References}

1. Mithoefer K, McAdams TR, Scopp JM, Mandelbaum BR (2009) Emerging options for treatment of articular cartilage injury in the athlete. Clin Sports Med 28: 25-40.

2. Mustonen AO, Koivikko MP, Lindahl J, Koskinen SK (2008) MRI of acute meniscal injury associated with tibial plateau fractures: prevalence, type, and location. AJR Am J Roentgenol 191: 1002-1009.

3. Curl WW, Krome J, Gordon ES, Rushing J, Smith BP, et al. (1997) Cartilage injuries: a review of 31,516 knee arthroscopies. Arthroscopy 13: 456-460.

4. Browne JE, Branch TP (2000) Surgical alternatives for treatment of articular cartilage lesions. J Am Acad Orthop Surg 8: 180-189.

5. Widuchowski W, Widuchowski J, Trzaska T (2007) Articular cartilage defects: study of 25,124 knee arthroscopies. Knee 14: 177-182.

6. Centers for Disease Control and Prevention (CDC) (2013) Prevalence of doctor-diagnosed arthritis and arthritis-attributable activity limitation--United States, 2010-2012. MMWR Morb Mortal Wkly Rep 62(44): 869-73.

7. Symonds T, Hughes B, Liao S, Ang Q, Bellamy N (2015) Validation of the Chinese Western Ontario and McMaster Universities Osteoarthritis Index in Patients From Mainland China With Osteoarthritis of the Knee. Arthritis Care Res (Hoboken) 67: 1553-1560.

8. Koch TG, Betts DH (2007) Stem cell therapy for joint problems using the horse as a clinically relevant animal model. Expert Opin Biol Ther 7: 16211626 .

9. Huey DJ, Hu JC, Athanasiou KA (2012) Unlike bone, cartilage regeneration remains elusive. Science 338: 917-921.

10. Williams R, Khan IM, Richardson K, Nelson L, McCarthy HE, et al. (2010) Identification and clonal characterisation of a progenitor cell sub-population in normal human articular cartilage. PLoS One 5: e13246.

11. Buckwalter JA (2002) Articular cartilage injuries. Clin Orthop Relat Res 402 21-37.

12. Brittberg $M$, Lindahl A, Nilsson A, Ohlsson C, Isaksson O, et al. (1994) Treatment of deep cartilage defects in the knee with autologous chondrocyte transplantation. N Engl J Med 331: 889-895.

13. Caldwell KL, Wang J (2015) Cell-based articular cartilage repair: the link between development and regeneration. Osteoarthritis Cartilage 23: 351362.

14. Alford JW, Cole BJ (2005) Cartilage restoration, part 1: basic science, historical perspective, patient evaluation, and treatment options. Am J Sports Med 33: 295-306

15. Logerstedt DS, Scalzitti DA, Bennell KL, Hinman RS, Silvers-Granelli $H$, et al. (2018) Knee Pain and Mobility Impairments: Meniscal and Articular Cartilage Lesions Revision 2018. J Orthop Sports Phys Ther 48: A1-A50. 
16. Bekkers JE, Inklaar M, Saris DB (2009) Treatment selection in articular cartilage lesions of the knee: a systematic review. Am J Sports Med 37 Supp 1: $148 \mathrm{~s}-155 \mathrm{~s}$

17. Mistry H, Connock M, Pink J, Shyangdan D, Clar C, et al. (2017) Autologous chondrocyte implantation in the knee: systematic review and economic evaluation. Health Technol Assess 21: 1-294.

18. Goyal D, Keyhani S, Goyal A, Lee EH, Hui JH, et al. (2014) Evidence-based status of osteochondral cylinder transfer techniques: a systematic review of level I and II studies. Arthroscopy 30: 497-505.

19. Goyal D, Keyhani S, Lee EH, Hui JH, et al. (2013) Evidence-based status of microfracture technique: a systematic review of level I and II studies. Arthroscopy 29: 1579-1588.

20. Filardo G, Andriolo L, Balboni F, Marcacci M, Kon E (2015) Cartilage failures. Systematic literature review, critical survey analysis, and definition. Knee Surg Sports Traumatol Arthrosc 23: 3660-3669.

21. Flood J (2010) The role of acetaminophen in the treatment of osteoarthritis Am J Manag Care 16 Suppl Management: S48-54.

22. Bruyere O, Cooper C, Pelletier JP, Branco J, Luisa Brandi M, et al. (2014) An algorithm recommendation for the management of knee osteoarthritis in Europe and internationally: a report from a task force of the European Society for Clinical and Economic Aspects of Osteoporosis and Osteoarthritis (ESCEO). Semin Arthritis Rheum 44: 253-263.

23. Ala Abdel Jalil, Robyn Gorski, Salah Abdel Jalil, Ryan Cronin, Michael Comianos, et al. (2019) Factors associated with diverticular bleeding and re-bleeding: A United States hospital study. North Clin Istanb 6: 248-253.

24. Arroll B, Goodyear-Smith F (2004) Corticosteroid injections for osteoarthritis of the knee: meta-analysis. BMJ 328: 869.

25. Caplan A, Fett N, Rosenbach M, Werth VP, Micheletti RG (2017) Prevention and management of glucocorticoid-induced side effects: A comprehensive review: Gastrointestinal and endocrinologic side effects. J Am Acad Dermatol 76: 11-16.

26. Colen S, van den Bekerom MP, Mulier M, Haverkamp D (2012) Hyaluronic acid in the treatment of knee osteoarthritis: a systematic review and metaanalysis with emphasis on the efficacy of different products. BioDrugs 26 : 257-268.

27. Zhang B, Thayaparan A, Horner N, Bedi A, Alolabi B, et al. (2019) Outcomes of hyaluronic acid injections for glenohumeral osteoarthritis: a systematic review and meta-analysis. J Shoulder Elbow Surg 28: 596-606.

28. Rutjes AW, Juni P, da Costa BR, Trelle S, Nuesch E, et al. (2012) Viscosupplementation for osteoarthritis of the knee: a systematic review and meta-analysis. Ann Intern Med 157: 180-191.

29. Jevsevar D, Donnelly P, Brown GA, Cummins DS (2015) Viscosupplementation for Osteoarthritis of the Knee: A Systematic Review of the Evidence. J Bone Joint Surg Am 97: 2047-2060.

30. Keeney M, Lai JH, Yang $F$ (2011) Recent progress in cartilage tissue engineering. Curr Opin Biotechnol 22: 734-740.

31. Ortega-Orozco R, Olague-Franco JK, Miranda-Ramirez E (2018) [Autologous chondrocytes implantation versus microfracture for the treatment of knee cartilage lesions]. Acta Ortop Mex 32: 322-328.

32. Chen X, McClurg A, Zhou GQ, McCaigue M, Armstrong MA, et al. (2007) Chondrogenic differentiation alters the immunosuppressive property of bone marrow-derived mesenchymal stem cells, and the effect is partially due to the upregulated expression of B7 molecules. Stem Cells 25: 364-370.

33. Aggarwal S, Pittenger MF (2005) Human mesenchymal stem cells modulate allogeneic immune cell responses. Blood 105: 1815-22.

34. Bartholomew A, Sturgeon C, Siatskas M, Ferrer K, Mclntosh K, et al. (2002) Mesenchymal stem cells suppress lymphocyte proliferation in vitro and prolong skin graft survival in vivo. Exp Hematol 30: 42-48.

35. Maitra B, Szekely E, Gjini K, Laughlin MJ, Dennis J, et al. Human mesenchymal stem cells support unrelated donor hematopoietic stem cells and suppress T-cell activation. Bone Marrow Transplant 33: 597-604
36. Xu L, Huang S, Hou Y, Liu Y, Ni M, et al. (2015) Sox11-modified mesenchymal stem cells (MSCs) accelerate bone fracture healing: Sox11 regulates differentiation and migration of MSCs. FASEB J 29: 1143-1152.

37. Yaghoubi $Y$, Movassaghpour A, Zamani M, Talebi M, Mehdizadeh A, et al. (2019) Human umbilical cord mesenchymal stem cells derived-exosomes in diseases treatment. Life Sci 233: 116733.

38. Pittenger MF, Mackay AM, Beck SC, Jaiswal RK, Douglas R, et al. (1999) Multilineage potential of adult human mesenchymal stem cells. Science 284 : 143-147.

39. Jahagirdar BN, Reinhardt RL, Schwartz RE, Keene CD, et al. (2002) Pluripotency of mesenchymal stem cells derived from adult marrow. Nature 418: 41-49.

40. Zuk PA, Zhu M, Mizuno H, Huang J, Futrell JW, et al. (2002) Multilineage cells from human adipose tissue: implications for cell-based therapies. Tissue Eng 7: 211-228.

41. Bi Y, Ehirchiou D, Kilts TM, Inkson CA, Embree MC et al. (2007) Identification of tendon stem/progenitor cells and the role of the extracellular matrix in their niche. Nat Med 13: 1219-12127.

42. Rui YF, Lui PP, Li G, Fu SC, Lee YW, et al. (2010) Isolation and characterization of multipotent rat tendon-derived stem cells. Tissue Eng Part A 16: 1549-1558.

43. De Bari C, Dell'Accio F, Tylzanowski P, Luyten FP (2001) Multipotent mesenchymal stem cells from adult human synovial membrane. Arthritis Rheum 44: 1928-1942.

44. Gronthos S, Mankani M, Brahim J, Robey PG, Shi S (2000) Postnatal human dental pulp stem cells (DPSCs) in vitro and in vivo. Proc Natl Acad Sci U S A 97: 13625-13630.

45. Lee OK, Kuo TK, Chen WM, Lee KD, Hsieh SL, et al. (2004) Isolation of multipotent mesenchymal stem cells from umbilical cord blood. Blood 103 : 1669-1675

46. Fukuchi $Y$, Nakajima H, Sugiyama D, Hirose I, Kitamura T, et al. (2004) Human placenta-derived cells have mesenchymal stem/progenitor cell potential. Stem Cells 22: 649-658.

47. In 't Anker PS, Scherjon SA, Kleijburg-van der Keur C, de Groot-Swings GM, Claas $\mathrm{FH}$, et al. Isolation of mesenchymal stem cells of fetal or maternal origin from human placenta. Stem Cells 22: 1338-1345.

48. Roobrouck VD, Ulloa-Montoya F, Verfaillie CM (2008) Self-renewal and differentiation capacity of young and aged stem cells. Exp Cell Res 314 1937-1944.

49. Kubosch EJ, Heidt E, Niemeyer P, Bernstein A, Südkamp NP, et al. (2017) In-vitro chondrogenic potential of synovial stem cells and chondrocytes allocated for autologous chondrocyte implantation - a comparison : Synovial stem cells as an alternative cell source for autologous chondrocyte implantation. Int Orthop 41: 991-998.

50. Zhou S, Greenberger JS, Epperly MW, Goff JP, Adler C, et al. (2008) Agerelated intrinsic changes in human bone-marrow-derived mesenchymal stem cells and their differentiation to osteoblasts. Aging Cell 7: 335-343.

51. Baxter MA, Wynn RF, Jowitt SN, Wraith JE, Fairbairn LJ, et al. (2004) Study of telomere length reveals rapid aging of human marrow stromal cells following in vitro expansion. Stem Cells 22: 675-682.

52. Hodgkinson CP, Gomez JA, Mirotsou M, Dzau VJ (2010) Genetic engineering of mesenchymal stem cells and its application in human disease therapy. Hum Gene Ther 21: 1513-1526.

53. Huang J, Zhang Z, Guo J, Ni A, Deb A, et al. (2010) Genetic modification of mesenchymal stem cells overexpressing CCR1 increases cell viability, migration, engraftment, and capillary density in the injured myocardium. Circ Res 106: 1753-1762.

54. Shen Z, Wang J, Huang Q, Shi Y, Wei Z, et al. (2018) Genetic modification to induce CXCR2 overexpression in mesenchymal stem cells enhances treatment benefits in radiation-induced oral mucositis. Cell Death Dis 9: 229 .

55. Grayson WL, Zhao F, Bunnell B, Ma T (2007) Hypoxia enhances proliferation 
and tissue formation of human mesenchymal stem cells. Biochem Biophys Res Commun 358: 948-953.

56. Foyt DA, Taheem DK, Ferreira SA, Norman MDA, Petzold J, et al. (2019) Hypoxia impacts human MSC response to substrate stiffness during chondrogenic differentiation. Acta Biomater 89: 73-83.

57. Jopling C, Boue S, Izpisua Belmonte JC (2011) Izpisua Belmonte, Dedifferentiation, transdifferentiation and reprogramming: three routes to regeneration. Nat Rev Mol Cell Biol 12: 79-89.

58. Fu X, Yang H, Zhang H, Wang G, Liu K, et al. (2016) Improved osteogenesis and upregulated immunogenicity in human placenta-derived mesenchymal stem cells primed with osteogenic induction medium. Stem Cell Res Ther 7: 138.

59. Poss KD, Wilson LG, Keating MT (2002) Heart regeneration in zebrafish Science 298: 2188-2190.

60. Jopling C, Sleep E, Raya M, Martí M, Raya A, et al. (2010) Zebrafish heart regeneration occurs by cardiomyocyte dedifferentiation and proliferation. Nature 464: 606-609.

61. Lepilina A, Coon AN, Kikuchi K, Holdway JE, Roberts RW, et al. (2006) A dynamic epicardial injury response supports progenitor cell activity during zebrafish heart regeneration. Cell 127: 607-619.

62. Pesaresi M, Sebastian-Perez R, Cosma MP (2019) Dedifferentiation, transdifferentiation and cell fusion: in vivo reprogramming strategies for regenerative medicine. FEBS J 286: 1074-1093.

63. Brockes JP (1997) Amphibian limb regeneration: rebuilding a complex structure. Science 276: 81-87.

64. Nye HL, Cameron JA, Chernoff EA, Stocum DL, et al. (2003) Regeneration of the urodele limb: a review. Dev Dyn 226: 280-294.

65. Kragl M, Knapp D, Nacu E, Khattak S, Maden M, et al. (2009) Cells keep a memory of their tissue origin during axolotl limb regeneration. Nature 460 60-65.

66. McGann CJ, Odelberg SJ, Keating MT (2001) Mammalian myotube dedifferentiation induced by newt regeneration extract. Proc Natl Acad Sc U S A 98: 13699-13704.

67. Camarda G, Siepi F, Pajalunga D, Bernardini C, Rossi R, et al. (2004) A $\mathrm{pRb}$-independent mechanism preserves the postmitotic state in terminally differentiated skeletal muscle cells. J Cell Biol 167: 417-423.

68. Bicknell KA, Coxon $\mathrm{CH}$, Brooks G (2007) Can the cardiomyocyte cell cycle be reprogrammed? J Mol Cell Cardiol 42: 706-721.

69. Engel FB, Schebesta M, Duong MT, Lu G, Ren S, et al. (2005) p38 MAP kinase inhibition enables proliferation of adult mammalian cardiomyocytes. Genes Dev 19: 1175-1187.

70. Hu T, Yao B, Huang S, Fu X (2019) Insight into cellular dedifferentiation in regenerative medicine. Sci China Life Sci.

71. Liu Y, Jiang X, Yu MK, Dong J, Zhang X, et al. (2010) Switching from bone marrow-derived neurons to epithelial cells through dedifferentiation and translineage redifferentiation. Cell Biol Int 34: 1075-1083.

72. Liu $Y$, Jiang $X$, Zhang $X$, Chen $R$, Sun $T$, et al. (2011) Dedifferentiationreprogrammed mesenchymal stem cells with improved therapeutic potential. Stem Cells 29: 2077-2089.

73. Poloni A, Maurizi G, Leoni P, Serrani F, Mancini S, et al. (2012) Human dedifferentiated adipocytes show similar properties to bone marrow-derived mesenchymal stem cells. Stem Cells 30: 965-974.

74. Rui Y, Xu L, Chen R, Zhang T, Lin S, et al. (2015) Epigenetic memory gained by priming with osteogenic induction medium improves osteogenesis and other properties of mesenchymal stem cells. Sci Rep 5: 11056.

75. Lin S, Lee WYW, Xu L, Wang Y, Chen Y, etal. (2017) Stepwise preconditioning enhances mesenchymal stem cell-based cartilage regeneration through epigenetic modification. Osteoarthritis Cartilage 25: 1541-1550.

76. Lin S, Lee WYW, Feng Q, Xu L, Wang B, et al. (2017) Synergistic effects on mesenchymal stem cell-based cartilage regeneration by chondrogenic preconditioning and mechanical stimulation. Stem Cell Res Ther 8: 221

77. Fortier LA, Barker JU, Strauss EJ, McCarrel TM, Cole BJ (2011) The role of growth factors in cartilage repair. Clin Orthop Relat Res 469: 2706-2715.

78. Hatakeyama Y, Tuan RS, Shum L (2004) Distinct functions of BMP4 and GDF5 in the regulation of chondrogenesis. J Cell Biochem 91: 1204-1217.

79. Blaney Davidson EN, van der Kraan PM, van den Berg WB (2007) TGF-beta and osteoarthritis. Osteoarthritis Cartilage 15: 597-604.

80. Deng ZH, Li YS, Gao X, Lei GH, Huard J (2018) Bone morphogenetic proteins for articular cartilage regeneration. Osteoarthritis Cartilage 26: 1153-1161.

81. van der Kraan PM, Blaney Davidson EN, van den Berg WB (2010) A role for age-related changes in TGFbeta signaling in aberrant chondrocyte differentiation and osteoarthritis. Arthritis Res Ther 12: 201.

82. Mohan N, Nair PD, Tabata Y (2009) 3D biodegradable protein based matrix for cartilage tissue engineering and stem cell differentiation to cartilage. $J$ Mater Sci Mater Med 20 Suppl 1: S49-S60.

83. Thorpe SD, Buckley CT, Vinardell T, O'Brien FJ, Campbell VA, et al. (2010) The response of bone marrow-derived mesenchymal stem cells to dynamic compression following TGF-beta3 induced chondrogenic differentiation. Ann Biomed Eng 38: 2896-2909.

84. Schmidt MB, Chen EH, Lynch SE (2006) A review of the effects of insulinlike growth factor and platelet derived growth factor on in vivo cartilage healing and repair. Osteoarthritis Cartilage 14: 403-412.

85. Shintani N, Hunziker EB (2007) Chondrogenic differentiation of bovine synovium: bone morphogenetic proteins 2 and 7 and transforming growth factor beta1 induce the formation of different types of cartilaginous tissue. Arthritis Rheum 56: 1869-1879.

86. Hunziker EB (2002) Articular cartilage repair: basic science and clinical progress. A review of the current status and prospects. Osteoarthritis Cartilage 10: 432-463.

87. Ge Z, Hu Y, Heng BC, Yang Z, Ouyang H, et al. (2006) Osteoarthritis and therapy. Arthritis Rheum 55: 493-500.

88. Davidson D, Blanc A, Filion D, Wang H, Plut P, et al. (2005) Fibroblast growth factor (FGF) 18 signals through FGF receptor 3 to promote chondrogenesis. J Biol Chem 280: 20509-10515.

89. Ahmed TA, Hincke MT (2010) Strategies for articular cartilage lesion repair and functional restoration. Tissue Eng Part B Rev 16: 305-329.

90. Raghunath J, Rollo J, Sales KM, Butler PE, Seifalian AM (2007) Biomaterials and scaffold design: key to tissue-engineering cartilage. Biotechnol Appl Biochem 46(Pt 2): 73-84

91. Yang D, Xiao J, Wang B, Li L, Kong X, et al. (2019) The immune reaction and degradation fate of scaffold in cartilage/bone tissue engineering. Mater Sci Eng C Mater Biol Appl 104: 109927.

92. Ge Z, Li C, Heng BC, Cao G, Yang Z (2012) Functional biomaterials for cartilage regeneration. J Biomed Mater Res A 100: 2526-2536.

93. Huang BJ, Hu JC, Athanasiou KA (2016) Cell-based tissue engineering strategies used in the clinical repair of articular cartilage. Biomaterials 98 $1-22$.

94. Ebihara G, Sato M, Yamato M, Mitani G, Kutsuna T (2012) Cartilage repair in transplanted scaffold-free chondrocyte sheets using a minipig model. Biomaterials 33: 3846-3851.

95. Chung C, Burdick JA (2009) Influence of three-dimensional hyaluronic acid microenvironments on mesenchymal stem cell chondrogenesis. Tissue Eng Part A 15: 243-254.

96. Engler AJ, Sen S, Sweeney HL, Discher DE (2006) Matrix elasticity directs stem cell lineage specification. Cell 126: 677-689.

97. Kemppainen JM, Hollister SJ (2010) Differential effects of designed scaffold permeability on chondrogenesis by chondrocytes and bone marrow stromal 
cells. Biomaterials 31: 279-287.

98. Serpooshan V, Julien M, Nguyen O, Wang H, Li A, et al. Reduced hydraulic permeability of three-dimensional collagen scaffolds attenuates gel contraction and promotes the growth and differentiation of mesenchymal stem cells. Acta Biomater 6: 3978-3987.

99. Vickers SM, Gotterbarm T, Spector M (2010) Cross-linking affects cellular condensation and chondrogenesis in type II collagen-GAG scaffolds seeded with bone marrow-derived mesenchymal stem cells. J Orthop Res 28: 11841192.

100.Bryant SJ, Nuttelman CR, Anseth KS (1999) The effects of crosslinking density on cartilage formation in photocrosslinkable hydrogels. Biomed Sci Instrum 35: 309-314.

101. Erickson IE, Huang AH, Sengupta S, Kestle S, Burdick JA, et al. (2009) Macromer density influences mesenchymal stem cell chondrogenesis and maturation in photocrosslinked hyaluronic acid hydrogels. Osteoarthritis Cartilage 17: 1639-1648.

102. Bian L, Guvendiren M, Mauck RL, Burdick JA (2013) Hydrogels that mimic developmentally relevant matrix and $\mathrm{N}$-cadherin interactions enhance MSC chondrogenesis. Proc Natl Acad Sci U S A 110: 10117-10122.

103.Zhu M, Feng Q, Bian L (2014) Differential effect of hypoxia on human mesenchymal stem cell chondrogenesis and hypertrophy in hyaluronic acid hydrogels. Acta Biomater 10: 1333-13340.

104. Xu J, Li J, Sien L, Wu T, Huang H, et al. (2016) Nanocarrier-mediated codelivery of small molecular drugs and siRNA to enhance chondrogenic differentiation and suppress hypertrophy of human mesenchymal stem cells. Advanced Functional Materials 26: 2463-2472.

105. Feng Q, Lin S, Zhang K, Dong C, Wu T, et al. (2017) Sulfated hyaluronic acid hydrogels with retarded degradation and enhanced growth factor retention promote hMSC chondrogenesis and articular cartilage integrity with reduced hypertrophy. Acta Biomater 53: 329-342.

106.Zhu M, Sun Y, Xu J, Feng Q, et al. (2016) Robust biopolymeric supramolecula "Host- Guest Macromer" hydrogels reinforced by in situ formed multivalent nanoclusters for cartilage regeneration. Macromolecules 49: 866-875

107.Xu J, Feng Q, Lin S, Yuan W, Li R, et al. (2019) Injectable stem cell-laden supramolecular hydrogels enhance in situ osteochondral regeneration via the sustained co-delivery of hydrophilic and hydrophobic chondrogenic molecules. Biomaterials 210: 51-61.

108. Schulz RM, Bader A (2007) Cartilage tissue engineering and bioreactor systems for the cultivation and stimulation of chondrocytes. Eur Biophys $J$ 36: 539-568.

109.Daly AC, Sathy BN, Kelly DJ (2018) Engineering large cartilage tissues using dynamic bioreactor culture at defined oxygen conditions. J Tissue Eng 9: 2041731417753718

110. Bian L, Fong JV, Lima EG, Stoker AM, Ateshian GA, et al. (2010) Dynamic mechanical loading enhances functional properties of tissue-engineered cartilage using mature canine chondrocytes. Tissue Eng Part A 16: 17811790.

111. Kock LM, Schulz RM, van Donkelaar CC, Thümmler CB, Bader A, et al. (2009) RGD-dependent integrins are mechanotransducers in dynamically compressed tissue-engineered cartilage constructs. J Biomech 42: 217721782.

112. Kelly TA, Ng KW, Wang CC, Ateshian GA, Hung CT (2006) Spatial and temporal development of chondrocyte-seeded agarose constructs in freeswelling and dynamically loaded cultures. J Biomech 39: 1489-1497.

113. Kisiday JD, Frisbie DD, Mcllwraith CW, Grodzinsky AJ (2009) Dynamic compression stimulates proteoglycan synthesis by mesenchymal stem cells in the absence of chondrogenic cytokines. Tissue Eng Part A 15: 2817-2824.
114. Mauck RL, Seyhan SL, Ateshian GA, Hung CT (2002) Influence of seeding density and dynamic deformational loading on the developing structure/ function relationships of chondrocyte-seeded agarose hydrogels. Ann Biomed Eng 30: 1046-1056.

115. Tee CA, Yang Z, Yin L, Wu Y, Han J, et al. (2019) Improved zonal chondrocyte production protocol integrating size-based inertial spiral microchannel separation and dynamic microcarrier culture for clinical application. Biomaterials 220: 119409

116. Lee D, Erickson A, Dudley AT, Ryu S (2019) A Microfluidic Platform for Stimulating Chondrocytes with Dynamic Compression. J Vis Exp 151.

117. Salinas EY, Hu JC, Athanasiou K (2018) A Guide for Using Mechanical Stimulation to Enhance Tissue-Engineered Articular Cartilage Properties. Tissue: Eng Part B Rev 24: 345-358.

118. McBeath R, Pirone DM, Nelson CM, Bhadriraju K, Chen CS (2004) Cell shape, cytoskeletal tension, and RhoA regulate stem cell lineage commitment. Dev Cell 6: 483-495.

119. Kelly DJ, Jacobs CR (2010) The role of mechanical signals in regulating chondrogenesis and osteogenesis of mesenchymal stem cells. Birth Defects Res C Embryo Today 90: 75-85.

120. Boeri L, Albani D, Raimondi MT, Jacchetti E (2019) Mechanical regulation of nucleocytoplasmic translocation in mesenchymal stem cells: characterization and methods for investigation. Biophys Rev 11: 817-831.

121. Bian L, Zhai DY, Mauck RL, Burdick JA (2011) Coculture of human mesenchymal stem cells and articular chondrocytes reduces hypertrophy and enhances functional properties of engineered cartilage. Tissue Eng Part A 17: 1137-1145.

122. Bian L, Zhai DY, Zhang EC, Mauck RL, Burdick JA (2012) Dynamic compressive loading enhances cartilage matrix synthesis and distribution and suppresses hypertrophy in hMSC-laden hyaluronic acid hydrogels. Tissue Eng Part A 18: 715-24.

123. Campbell, J.J., D.A. Lee, and D.L. Bader, (2006) Dynamic compressive strain influences chondrogenic gene expression in human mesenchymal stem cells. Biorheology 43: 455-470.

124. Pelaez D, Huang CY, Cheung HS (2009) Cyclic compression maintains viability and induces chondrogenesis of human mesenchymal stem cells in fibrin gel scaffolds. Stem Cells Dev 18: 93-102.

125. Scalzone A, Ferreira AM, Tonda-Turo C, Ciardelli G, Dalgarno K, et al. (2019) The interplay between chondrocyte spheroids and mesenchymal stem cells boosts cartilage regeneration within a 3D natural-based hydrogel. Sci Rep 9: 14630

126. Huang CY, Hagar KL, Frost LE, Sun Y, Cheung HS (2004) Effects of cyclic compressive loading on chondrogenesis of rabbit bone-marrow derived mesenchymal stem cells. Stem Cells 22: 313-323.

127. Arnsdorf EJ, Tummala P, Kwon RY, Jacobs CR (2009) Mechanically induced osteogenic differentiation--the role of RhoA, ROCKII and cytoskeletal dynamics. J Cell Sci 122: 546-553.

128. McMahon LA, Reid AJ, Campbell VA, Prendergast PJ (2008) Regulatory effects of mechanical strain on the chondrogenic differentiation of MSCs in a collagen-GAG scaffold: experimental and computational analysis. Ann Biomed Eng 36: 185-194.

\section{Acknowledgement}

This study was supported by National Natural Science Foundation of China China (81874000), Natural Science Foundation of Guangdong Science and Technology Department (2018A030313374 and2016B030309002), and partially supported by Stem Cell Preclinical Research Projects of the Affiliated Hospital of Guangdong Medical University(2018PSSC001) Special Funds for the Cultivation of Guangdong College Students' Scientific and Technological Innovation ("Climbing Program" Special Funds) (pdjh2019b0213), Students Innovation Experiment Program of Guangdong Medical University (FZZY001) and open fund of Marine Biomedical Research Institute, Guangdong Medical University. 